\title{
CHAPTER 18
}

\section{Manankurra}

\section{What's in a name? Placenames and emotional geographies}

\author{
JOHN J. BRADLEY AND \\ AMANDA KEARNEY
}

\section{Introduction}

A thousand kilometres south-east of Darwin, as the 'crow flies' is Borroloola. Sixty kilometres east of Borroloola is the place Manankurra; occupying the east bank of a large bend on the Wearyan River. In the late afternoon sun the eastern banks of the river at Manankurra glow in deep ochre shades of yellow and red, while saltpans span the horizon, reaching out to the sea, the very essence of Yanyuwa life and Law. The white barked eucalypts stand starkly pale, skeletal against the solid trunks and olive green fronds of giant trees appearing as if from an ancient world. These are cycad palms; they stand in crowds along the river bank and retreat into the east, south and west. It is the cycad palms that are the focus of this place, that give meaning to its name. They are the first point of introduction to this place and their physical and cultural significance crosses the boundary of land belonging to the Yanyuwa and Garrwa people, neighbouring Aboriginal groups in the south-west Gulf of Carpentaria, northern Australia. Manankurra holds power in place and in all time, with a rich and complicated narrative of engagement for the Yanyuwa, as Indigenous owners.

As a place Manankurra has never been known by any other name. It still appears on maps, admittedly written in the older style orthography (Manangoora) (Bradley et al. 1992). Manankurra is wirrimalaru ${ }^{1}$ - a 'big place' and still, despite not being permanently inhabited by Yanyuwa people for many decades, occupies a central position in the minds and musings of people today. It is defined by an emotional geography that makes it the social and ritual centre of Yanyuwa country. It is described as being 'big', 'like politicians' (Annie Karrakayn pers. comm. 1988). In this paper we turn to the physical and social 
characters of Manankurra, to draw on the compelling details of the emotional geography that accompanies the name 'Manankurra'. The naming of place is a powerful act, a privilege acted out by Yanyuwa ancestors a long time ago. The power of this act is not lost on Yanyuwa people today, for placenames are more than remnants of an earlier time; they deny any notion of an innocent or arbitrary history (see Kearns and Berg 2002: 285). Instead, names are embedded and implicated in the very way that Yanyuwa people engage their homelands, how they transmit narratives today and how they educate their children and visitors to their country. The Yanyuwa rarely adopt 'whitefella names' (nonIndigenous placenames) that have been imposed across their homelands since European contact began in the late 1800s. Manankurra itself has not been re-authored or given any other name, despite this happening elsewhere. A resistance to ever renaming this place highlights the tension of a contested landscape in post-contact times, in which two or more elocutions of the land and sea are often found, betraying a history of ongoing colonisation and Indigenous struggles to claim and author their own homelands (see Kearns and Berg 2002: 286). Kearns and Berg (2002: 286) recognise a similar practice in New Zealand, noting that Maori resistance to naming occurs on at least two levels: the creation and deployment of alternative names and the use of alternative pronunciations for established names. To understand this struggle we turn to memory and the act of remembering a placename and the events that mark its narrative journey: the emotional geography of this place. Memory and remembering re-invigorate place, irrespective of land tenure, visitation or access arrangements. The primacy no longer resides in a physical connection with Manankurra, for this is no longer possible for most Yanyuwa. Today, it is the emotional and political geographies, made up of events, moments and circumstances that draw this place close again, and trigger remembering. It is held that Manankurra, like other powerful places, is always there, it always endures (see Figure 18.1).

There are times when Manankurra is brought back onto centre stage and into the forefront of people's memory and lives, while at other times it sits quietly in the individual and group memory. This is for a complex range of reasons. Remembering is at once an act of identity enforcement, land, place and ancestor articulation, and the enacting of Law. For this place, "memory crystallizes and secretes itself" (Nora 1989: 7 in Hoelscher and Alderman 2004: 350), a process that began when the ancestors called the name 'Manankurra'. Remembering is dynamic and central in the maintenance and contestation of Yanyuwa homelands as part of a political identity in the world today (e.g. Hoelscher and Alderman 2004: 348). 
Figure 18.1: Placenames within a four kilometre radius of Manankurra. Adapted from a ground drawing by senior Yanyuwa women Dinah Norman Marrngawi, Eileen McDinny Manankurrmara and Ida Ninganga. This ground drawing illustrates the complexity of landscapes and placenames, and in naming the placename Manankurra you implicate many other places and also bring their biography into being and remembrance.

\begin{tabular}{llll}
\hline$\uparrow$ North & Wukuri & Mirrinda & \\
\hline & $\begin{array}{l}\text { Lhunurnda } \\
\text { Liwarnnya }\end{array}$ & & Mungkukurinda \\
& Liwurriya & & Mungkurrangatha \\
Jikangarrma & & Malamalaburri & Lilanmarrila \\
Jarramba & Arlkujarra & Manankurra & Maabayn \\
Kawajbawilangka & & Nikarrila & Rudinya \\
& & Liwarlamuwa & Yunbanbalaya \\
& & & Wanmari
\end{tabular}

\section{Emotional geographies and place}

An emotional geography concerns the social and sensory relations that define place. Patterns in human engagement have an effect on place, the individual and group. The experiential processes of cultural habitus, that ultimately shape cultural identity, are dominant in shaping emotional encounters with place. Yanyuwa relationships with their homelands and ancestors are defined by an understanding that humans have an effect on country only to the extent that they are emotionally engaged with it (Bradley 1997: 177). ${ }^{2}$ Emotion is the affective state of consciousness that is experienced in engagements with homelands and for the Yanyuwa these can range from love, nurturing concern, fear, anger, bewilderment, sadness and loneliness. Emotional engagements shaping human interactions with place are a key feature of Yanyuwa oral histories and contemporary narrative. When speaking of country Yanyuwa people often express their relationship to the land and sea as one of kin, affection, warmth, closeness, fear and responsibility. This is because all Yanyuwa people hold specific relationships, roles and responsibilities as bestowed on them through paternal and maternal descent. These relationships govern the place of an individual, family and clan group within the Yanyuwa world of meaning. They anchor the individual to country and carry great emotional and political weight for Yanyuwa people as they are pivotal to Yanyuwa Law and cultural autonomy. 
An approach that blends emotional and political geographies of place is not unlike Davidson and Milligan's notion of an 'emotio-spatial hermeneutic', in which "emotions are understandable - 'sensible' - only in the context of particular places" (Davidson and Milligan 2004: 524). Recollections of place, one's relationship to it, and the calling of placenames represent articulations of emotion that are "spatially mediated in a manner that is not simply metaphorical". It is as Davidson and Milligan write: "emotional relations and interactions weave through and help form the fabric of our unique personal geographies" (Davidson and Milligan 2004: 523). For the Yanyuwa, placenames are spoken and brought into being for cultural, political and emotional motivations. The form and expression a placename takes - as called by the ancestor and all successive generations of people - reflects and contributes to the constitution of their community and that of their neighbours. Of the Tiger Shark Ancestor, who called and created Manankurra, Yanyuwa woman Dinah Norman says:

Nya-mangaji adumu ka-arri baji kilu-wundarrbanthaninya Manankurra na-wini awara Manankurra bajawarnu jangambala-wundarrbanji Manankurra.

The Tiger Shark (ancestor) he was there and he called into being Manankurra, the name of the country is Manankurra and it is in this same way that we are naming the place Manankurra. (Dinah Norman Marrngawi pers.comm. 1986)

Etymologically the name 'Manankurra' is said by the Yanyuwa to be a 'name from the beginning', a name 'that the Tiger Shark put there'. It is possible that the name 'Manankurra' contains the ma-food class prefix (see Bradley et al. 1992) and the verb root-kurra-meaning 'to bury', and thus would relate to the process of burying halved cycad kernels (ma-mawirl) in trenches to leach out the poison. The Yanyuwa rarely engage in etymological processes such as this but more often assert that placenames are not transparent in their translation, and simply 'are', because the ancestors made them so. As Kearns and Berg explain, a placename involves a "proclamation of cultural politics" and not an exercise in linguistics, rather, "placenames can be considered to be one of the material and symbolic artefacts of culture" (Kearns and Berg 2002: 283, 284).

According to Yanyuwa belief, the cycad palms (ma-rnbaka) that spread out from the central focal site of Manankurra were deposited there by the Tiger Shark Spirit Ancestor (Yulungurri) who travelled from the southern Gulf of Carpentaria in the formative period popularly known in the West as the Dreaming (Bradley 1988a) (see Figure 18.1). This Tiger Shark is associated with the Yanyuwa Rrumburriya semi-moiety, a clan grouping to which certain individuals trace their descent. For the Yanyuwa there are four kinship groupings or semi-moieties, which match onto four lines of patrilineal descent. 
Each person traces their descent accordingly and is given membership into one of the four clan groups, Mambaliya-Wawukarriya, Rrumburriya, Wuyaliya or Wurdaliya. Manankurra is considered Rrumburriya clan country. Some 10 kilometres upstream, on the Foelsche River, is the equally important site of Rocky or Kalalakinda. This site is associated with the Garrwa Wurdaliya semi-moiety, the Garrwa being a neighbouring language group. For the Garrwa people the distribution of the cycad palm over their country is the result of the activities of a group of human-like Spirit Beings (Ngabaya). Ngabaya acquired the cycad from the Tiger Shark Ancestor and in doing so gained control over the power songs associated with the toxic cycad fruit, and the knowledge to process this resource. In Yanyuwa narrative the distribution of cycads beyond Manankurra and into Garrwa country is explained as follows:

And there was to the south a Spirit Man at Kalakakinda [a place at Rocky on the Foelsche River] and he spoke to the Tiger Shark saying, 'Hey! Give me your power songs for the poison that the cycad fruit contains, ${ }^{3}$ you live in the water, you are an inhabitant of the sea, while I am a man, a fully initiated man, give the things I ask for to me!' It was in this way the Spirit Man spoke and the power songs belonging to the cycad fruit came to belong to the [Garrwa] Wurdaliya people. (Bradley 1988a: 14)

The area of land that encompasses the central focal site of Manankurra, and the greatest stand of cycad palms, is called by the general Yanyuwa regional placename of 'Ma-wirla' (see Figure 18.1). The term defies word-for-word translation; rather, it carries meanings of a place with abundant vegetable food, a place where many people could come together for ceremonies and for other important events. The following quotation, that comes from a senior owner of the Manankurra area, directly addresses the cycad palm as a site of social signification that at once includes and transcends its value as a food item:

That cycad food that is the food that reared me from the time I was a baby to my womanhood. Truly it is good food, when one eats that food one becomes replete, not like the bread of whitemen it does not fill you. The cycad food on the other hand fills people, they grow strong and they are healthy, I was reared on that food, all of us old people we yearn for that food, truly it is a food with a quality of excellence. (Minnie Wulbulinimara pers. comm. 1980)

Also associated with Manankurra is the song-line ( $k u j i k a)$ of the Tiger Shark. ${ }^{4}$ This begins at Manankurra and travels back out to the sea and the islands (Yanyuwa Families et al. 2003). People often comment that the Tiger Shark sang his song backwards, beginning his journey as such: 
The eye, the well [water source] of the Tiger Shark is there at Manankurra, it is there that the Tiger Shark climbed up singing, the shark was at the well singing, he was sending his song back to the country where he had travelled, we are naming the well Dungkurrumaji, my father's name. The Tiger Shark was at the well singing and so it is we are singing the well and the trees that surround it, then we are singing the double-barred finches and the bar-shouldered doves that come to drink at the well. Onwards then we are carrying the song and we are singing the very tall cycad palms which have as their personal name Yulungurri, the same as the shark, then we are singing the white barked gum tree which is named in the song as Karrijiji, the same name as my father's brother. We are singing northwards, and we descend down into the depths of the river. We are singing the mouth of the shark. Down in the depths of the river we are singing, we sing the bundle of soaking cycad and we follow the high tide when the current is flowing strongly downstream. We continue singing northwards and then we are climbing, up onto the riverbank, onwards now along the riverbank we are singing. We are singing the tall steep sides of the eastern riverbank, it is the mainland, yes we are still singing on the mainland, we are singing the camps for the old people. We are singing the children who will not stop talking, we sing the bark canoes and the old man making the fishing net, the cycad bread and the footpaths along the top of the riverbank. Then onwards and northwards we follow the path of this song; in its fullness and completeness we are singing it ... (Ron Ricket Mururndu pers. comm. 1988)

There is certain intensity to this narrative, one of constant movement, the continuous use of present tense, and the speaker imagines himself following the path of the song. The song at once embodies the Tiger Shark, and the singer, reinforcing the identities of both through singing action. The very singing of the song makes important claims to kinship and naming, thus activating relationships and emotion in the present day. The song line is not of the past, it can only be of the present as it rolls across the tongue of its singer. For the Yanyuwa, songlines are always described using present tense verbs, never past; the actions may be of the past but what was left there is always of the present. Songlines are described as: ja-wingkayi 'he is moving', ja-wulumanji 'he is running', and ja-wujbanji 'he is flowing', indicating the affective consciousness of the singer who brings these actions into being by singing them. For those with the mouth to sing, the eyes to see and ears to hear, Manankurra is a permanent reminder of the body and knowledge of the Tiger Shark.

In another emotive narrative of Manankurra, Eileen McDinny Manankurrmara, a senior owner for this place, recalls that: 
This food of strength, this cycad food or great importance, all of the old people they used to gather together here at Manankurra, they would come from the south and all the islands. They would gather here because of this cycad food, they would gather it and wrap it up in paperback bundles or paperback dishes. We grew up on this food ... I was taught by my aunt, she who was named Manankurrmara. Alright listen to me again, I will tell you it was not just the Yanyuwa speakers and the Garrwa speakers who wanted this food, the whitemen who used to live here, old Bill Harney and Horace Foster and Andy Anderson when they had no flour or food left it was this cycad food they would eat ... white and black together we all ate this food ... This food, this cycad food is for us, it is of great importance, and it was important for those who lived a long way away from this place, they used to come here for the fighting grounds that are here in the north and they used to fight with boomerangs and duelling clubs, those who used to eat this food; this food my senior paternal grandfather ... Oh this dear country of mine Manankurra it is too quiet it was not like this in past times, this country here at Manankurra and the islands to the north and south to Kalalakinda and west to Wubunjawa all of these places moved with people, they are now all dead, this country is too quiet, once there were the sounds of people singing, laughing, swearing and crying, there is nothing, now there is only us and we live west at Borroloola. (Eileen McDinny Manankurrmara 1986 in Yanyuwa Families et al. 2003: 185-187)

People still care deeply for Manankurra. While the placename may be used in regular conversations about country and old times, any direct and detailed conversation about Manankurra requires certain etiquette. People often begin by asking; 'Is it alright if I call the name of that place?' - yamulhu barra karmawandarrbala na-wini awara? This is a question usually asked by someone who is deemed junior to the listeners. It gives the listeners the chance to say 'yes, keep going' or sometimes to abruptly say, 'No, you do not know that place!' kurdardi, yinda manji barra ki-awaruwu! In such instances, the presumption that underpins the outright calling of a placename is tantamount to saying that you know many levels of knowledge about that place as well. In many respects Yanyuwa people empower Manankurra more because this part of country, more so than others, has been reorganised and challenged by outside influence, to which Yanyuwa people responded by maintaining and persisting in the Law for Manankurra.

The right to name or call a place, even one as well known as Manankurra, is highly contested. It depends on familiarity, knowledge and permission. To call a name without authority can result in the individual being seen to act out of order, in which case he or she does not know what that place contains and 
does not comprehend its Law. Unfortunately this is often the case with drunken people who offend the sensibilities of those who know and are able to call the name of a place. It is also an issue for younger people who do not know how to call the name or sing the kujika - song-line - of country because they have never been there. What is witnessed then is a distinction between the ability to know a name and the power to bring a name into being. The separation of knowing and being is reflected in people's memories of Manankurra and one can get a sense of the individual's experience of this place by the manner in which the person tells their story. Knowing a place and practising its Law brings it into being, in an entirety that cannot be achieved by a word only. It is knowledge of Aboriginal Law that is essential to the naming and calling of Manankurra.

Ultimately 'memory' and the power of remembering becomes the crucial pivot of all this, because it is by dint of reliance on memory that connections are made. Educating young people in Yanyuwa language and song, in formats they can comprehend, are some of the means by which elders transmit Law across generations. Meaning of the highest prestige comes when the interconnectedness of things is fully realised. The interconnectedness of things, all elements that contribute to the status, nature, engagement and management of place, is differentially understood today. While it can be fully realised by elder Yanyuwa people and those who have experienced something of life and Law at Manankurra for many years, for younger people, their notion of interconnectedness calls upon other elements. For younger generations it is politics, their own histories and those of their families and talk of an 'old days', so different to today, that defines their relationship and connectedness to place. Connections remain by virtue of their birthright and kin. Younger Yanyuwa people work towards an understanding of Manankurra that is the same but different to that held by their old people and the ancestors. Negotiating these meanings is an ongoing struggle to define Yanyuwa identity in a rapidly shifting and highly politicised social, political and economic Australian cultural landscape. It is the vital link between places and the inter-generational sharing of memorial narratives that has ensured an endurance of Yanyuwa identity and cultural autonomy in a world of invading elements and acts of colonial dispossession.

Through the act of remembering, people trigger emotional and political engagements with Manankurra. This involves drawing on their position in the world in relation to their old people, while mindful of their future. It is not merely an act of looking back at times past. This distinction is imperative to understanding the ongoing importance of Manankurra after years of physical alienation from this place. In line with phenomenological thinking, people's experience of the world is dually embodied in a physical and social encounter. Places represent the physical while the terms on which place is apprehended relate to the social. How Yanyuwa people perceive Manankurra is telling of who 
the Yanyuwa are. As Merleau-Ponty observed, perception (of place) is more than a sensory stimulation but is an action that involves a construction of meaning; that is, "something (a meaningful object) is seen by somebody (a perceptual subject)" (Crossley 1994: 9). As sentient, practical and affective beings, human agents encounter the world in terms of perception, engagement and experience. As Crossley (1994: 14) writes, the seer and the seen are relationally constituted and the relationship is an embodied one. If as Merleau-Ponty (1962) writes, perception "occurs not in the head but in front of the subject and it brings the perceiving subject as well as the perceived object into being" (Crossley 1994: 14), then Yanyuwa people, as the perceptual subject, and Manankurra, as the perceptual object bring each into being.

Indigenous narrative linked to Manankurra extends far back to ancestral times. Oral testimonies stand to represent the times of the old people, and transmission of these narratives is held to be one of the greatest responsibilities residing with today's elders and learned individuals. Early ethnography and anthropological accounts have also contributed to the record of Manankurra over the years (see Avery 1978, 1983; Avery and McLaughlin 1977; Baker 1989, 1990a, 1990b, 1992, 1993, 1999; Bradley 1988a, 1988b, 1991, 1995, 1997, 2001, 2006; Bradley et al. 1992; Kearney 2005, 2008, 2009, Kearney and Bradley 2006). Manankurra has always been an important base for the Yanyuwa. From here, people would travel to mainland locations and to the offshore islands. Access to marine resources coupled with the available mainland resources in the area, have long made it an optimal location for long term visitation and camping. Manankurra satisfied all the requirements of a 'big place' in that it has the close juxtaposition of fresh drinking water and associated mainland resources with easy access by river to marine resources and for meetings with neighbouring groups.

1918 saw the establishment of permanent non-Indigenous settlements at Manankurra. The first European to permanently reside in the area established what was to be a long-term salt production enterprise (Baker 1999: 47-49). The salt works at Manankurra created seasonal employment for Aboriginal people in the region, particularly Yanyuwa and Garrwa people. Efforts to tap into a labour source, coupled with a tendency on the part of Europeans to settle at locations on Yanyuwa country known either for their resource richness or ability to support large numbers of people camping in the area, is not uncommon in the post-contact history of the region (see Baker 1990b). The availability of key resources in and around the Manankurra area was clearly an influencing factor in European settlement across the landscape. In a feed-through effect, the presence of Europeans at Manankurra and the establishment of seasonal employment in many senses shaped the nature of Yanyuwa settlement and visitation of existing and new camps in the area. Commercial salt production 
ceased around 1941, by which stage the Yanyuwa people had established a large campsite on the eastern bank of the Wearyan River, across from the European settlement at Manankurra.

The cross-cultural encounters at Manankurra began in the early to mid 1900s. These times in themselves were relatively unproblematic and the contact not so pervasive that Yanyuwa people and their neighbours significantly changed the patterns and habits of their daily and ceremonial lives. Aboriginal people took up work around Manankurra, but maintained the habit of seasonal movement across the land and seascape. It was after the 1940s that this habit of settlement and people's practices and engagements with Manankurra began to shift. After the 1940s Yanyuwa people established a large campsite on the eastern bank of the Wearyan River, across from what had become a dominant European settlement at Manankurra. The establishment of a new camp, at Liwurriya, across the river expresses the relative closeness and distance characterising Yanyuwa and European relations at this time. Cultural competition over the Manankurra area created the context for a geographical shift in people's daily and ceremonial lives. Subsequently, visitation to the Manankurra area, including permanent settlement at Liwurriya, eased after the 1950s when people were living on a permanent basis in the township of Borroloola - established as a colonial outpost in the late 1800s. Since this time intense discussion and memorialising of Manankurra has occurred. The reasons for people leaving Manankurra and Liwurriya as permanent or semi-permanent settlements are complex and the move is best understood as the result of a series of influencing factors, rather than any one cause, brought to bear in post-contact times (see Baker 1999).

Today Manankurra is contained within a pastoral lease. Granted in 1964, the lease consumes the traditional country of Yanyuwa and Garrwa people. Speaking of these land arrangements, one senior Yanyuwa man defiantly and sadly stated:

Long time people have been there for ceremony, but nothing today ... he been good before but no more ... I'm sorry for country. Aboriginal land, white man lease over the top, but you can't get him under ground, you can't get that one. They been cheeky [dangerous] longa that station, you can't kill em that lease. Manankurra still there and still strong ... we want that land for ceremony and kujika [songline] white man taking all the land from Aboriginal people. (Dinny McDinny Nyilba pers. comm. 2002)

There remains a degree of impassioned resentment towards land arrangements at Manankurra. Interestingly this is not directed at the actual leaseholders, but rather focuses on overall processes of ongoing colonisation of Yanyuwa homelands. Many elders speak of their relationships with the lease- 
holders in terms of kin and family connections, alluding to the cross-cultural relationships that are very much a part of the lived history of Yanyuwa lives and country. Senior Yanyuwa and Garrwa men have often stated with great force that the current lease-holder is 'okay for country', but simultaneously will emphasise that Manankurra is a proper Yanyuwa place, and that despite decades of contest as to the 'ownership' of this area, people have not lost sight of this rightful ownership.

Part of what has triggered or propelled Yanyuwa engagements - of the emotional and political kind - with Manankurra in recent years are the challenges to Yanyuwa cultural authority over this place. This has been matched by such actions as a proposal, on the part of Yanyuwa men and women, for a land excision within the leased area. This concerned a piece of land located near the old camp of Manankurra. This cultural assertion was made in a commitment to uphold responsibility for the land's physical and emotional wellbeing. The proposal was a complicated affair and the pastoral leaseholders expressed great concern over this action. Much of this was fuelled by a nationwide concern concerning Indigenous land rights in northern Australia. It was a desire to be back on 'country', to manage and engage through intimate presence that motivated the proposal. Yanyuwa elders today still recall this event, recalling that there are too many outsiders at Manankurra, fuelling a "jealousy for land" that situates Yanyuwa interests as peripheral (Annie Karrakayn pers. comm. 2004).

In 1988, a group of Yanyuwa people participated in a walk from Borroloola to Manankurra. This event was recorded on film in Journey East/Buwarrala Akarriya. The film tracks the journey of Yanyuwa families crossing through savannah country, over rivers, moving through the country of their ancestors. Travelling to Manankurra was a profound moment for all who took the journey, and in 2006 young and old Yanyuwa people still speak of this, and remember the individuals, the places, the excitement and their arrival at the Wearyan River. Amongst this group of travellers were older men and women, young adults, teenagers and children. Pivotal to the journey was the presence of three young boys or rdaru - young initiates. Taking initiates on this journey was deemed an act of proper Law necessary to portray the manner in which the 'old people' moved through country in times past. People recall that as they moved closer to Manankurra smoke rose into the sky, signalling that people were there, waiting for their arrival. It is recalled that the journey "was like heading to a capital city, just like the old days the smoke was burning on the horizon, it was like the past in the present" (Bradley 2006). Upon her return to Manankurra, Dinah Norman Marrngawi, who holds the powerful bond of nyankarra ${ }^{5}$ to this area of her mother's country, recalled "we think of old people and been crying for that country". 
Manankurra, although physically alienated from most Yanyuwa people's lives today, is invariably re-engaged with the onset of circumstances or events that trigger remembering. In recent times, events have caused this place to remain a part of the Yanyuwa cultural and emotional landscape - through memory. Features that revive Manankurra are the assertion of land rights and demands for a land excision, circumstances and events such as the physical alteration of the landscape and cutting down of cycads by non-Yanyuwa people, filming Journey East, exceptional flooding of the Manankurra landscape, the onset and expansion of commercial crabbing and fishing industries along the Wearyan River, and the death of several elders strongly associated with Manankurra and neighbouring ma-wirla country. Each of these is in turn underlined by an emotive dialogue fuelled by rumour, gossip and innuendo surrounding the pastoral lease, occasional visits of lease-holders to Borroloola and the presence of researchers, anthropologists, lawyers and archaeologists who desire to know more of Manankurra and the wider region. All of these factors prompt people to recall their 'master story' of Manankurra, which informs an ongoing emotional geography of this place.

A placename ignites memory, etiquette, relationships, fondness and sadness. Whether it is a young man who travelled this country as an initiate, a woman whose namesake or bush name ${ }^{6}$ derives from the ancestors of this place, an older man who now stands as appointed custodian of this place, or a young child who hears stories of the old days from his or her grandmother, this place remains a part of Yanyuwa people's lives. Emotive narratives informed by cultural habit and experience are the 'connective tissues' that link people's memory of Manankurra to a place in the east of Yanyuwa homelands. "Remembering is not random" (Sharp 2002: 54), and memory has more to do with who stores the information and the way things are stored than what is stored. While the nature of memories may vary across generations, the consistency is that all Yanyuwa people know Manankurra, they know the Tiger Shark Ancestor and they understand to some extent what this place has always been. As it is so intimately linked to identity for these people, it is suffused with notions of value, affect, and strength.

Yanyuwa people have over 1500 placenames across their homelands and the forces of memory are so powerful in some people that they can call into being events associated with a vast number of them. In more recent times this has been undertaken and witnessed in people's participation in the litigated process of land claims. Knowledge and Law associated with all of these places has emotional dimensions, and becomes the means by which groups of people and individuals negotiate the world around them. These negotiations, especially in relation to that which is considered sacred, include the legitimacy of claims to privileged knowledge, connections to place and people, to the past, the present 
and also the future. Caring for country in Yanyuwa culture is about both feeling emotionally attached to a place; and engaging to effect change in the world around, to care for it, to encourage the presence or absence of animals, ancestors and seasonal shifts, through emotionally engaging with Law, ancestors and a discrete body of knowledge that is Yanyuwa Law (Bradley 1995, 2001; Rose 1996, 2000; Rose and Clarke 1998).

The events of the past have shown that the Yanyuwa people attempted to retain an attachment to place, firstly with resistance and accommodation of a non-Indigenous presence in the region (which saw them work alongside and for Europeans in the region), secondly by shifting their physical proximity to place (by moving across river to Liwurriya), and lastly by keeping strong emotional and conceptual links to place in the face of physical exile. The act of asserting a position within a contested space is a recurrent theme across colonial landscapes, where the land is the greatest object of desire and to which foreign elocutions of place become commonplace. Yanyuwa accounts of their homelands assert the position of several powerful places such as Manankurra. By virtue of their identities Yanyuwa people remember their homelands, the status and Law attached to place. In doing so they perpetually re-inscribe a social memory to place and infuse the placename with a wealth of meaning that is equal parts drawn from the stories of the 'old people' and today's affective and political consciousness.

\section{References}

Avery, J. 1978, 'Aboriginal Land Rights: The View from Borroloola', National Times, 22 July 1978.

- 1983, 'The Recent History of the Borroloola Aboriginal People and their Struggle for Land Rights', in We Are Bosses Ourselves: The Status and Role of Aboriginal Women Today, F. Gale (ed.), Australian Institute of Aboriginal Studies, Canberra: 62-65.

- and McLaughlin, D. 1977, Submission by Northern Land Council to the Aboriginal Land Commissioner on the Borroloola Region Land Claim, 27 September 1977, Northern Land Council, Darwin.

Baker, R. 1989, 'Yanyuwa Contact History: The Value of Oral Sources', Oral History Association of Australia Journal, no. 11: 30-41.

- 1990a, 'The Impact of Tourism on the Aboriginal Community of the Borroloola area of the Northern Territory', paper presented to the Australian Institute of Aboriginal and Torres Strait Islander Studies, Remote Aboriginal and Torres Strait Islander Community Futures Conference, Townsville, 12 July. 
- 1990b, 'Coming In: The Yanyuwa as a Case Study in the Geography of Contact History', in Terrible Hard Biscuits, V. Chapman and P. Read (eds), Allen \& Unwin, New South Wales: 123-166.

— 1992, 'Gough Whitlam Time: Land Rights in the Borroloola Area of Australia's Northern Territory', Applied Geography, no. 12: 162-175. (Also published in Indigenous Land Rights in Commonwealth Countries: Dispossession, negotiation and community action, Proceedings of a Commonwealth Geographic Bureau Workshop, Christchurch, February 1992, Department of Geography, Christchurch University.)

- 1993, 'Traditional Aboriginal Land Use', in Traditional Ecological Knowledge: Wisdom for Sustainable Knowledge, N. Williams and G. Baines (eds), Centre for Resource and Environmental Management, The Australian National University, Canberra: 126-143.

- 1999, Land Is Life: From Bush to Town: The Story of the Yanyuwa People, Allen \& Unwin, Sydney.

Beaton, J. 1977, 'Dangerous Harvest', PhD thesis, The Australian National University, Canberra.

Bradley, J. 1988a, Yanyuwa Country: The Yanyuwa people of Borroloola tell the history of their land, translated and illustrated by J. Bradley, Greenhouse Publications, Melbourne.

— 1988b, 'Yanyuwa: "Men Speak One Way, Women Speak Another"', Aboriginal Linguistics, no. 1: 126-134.

- 1991, 'LI-MARAMARANJA: Yanyuwa Hunters of Marine Animals in the Sir Edward Pellew Group, Northern Territory', Records of the South Australia Museum, vol. 25, no. 1: 91-110.

- 1995, 'Fire: Emotion and Politics: A Yanyuwa Case Study', in Country in Flames: Proceedings of the 1994 Symposium on Biodiversity and Fire in Northern Australia, D. B. Rose (ed.), Biodiversity Unit, Department of the Environment, Sport and Territories, and the North Australia Research Unit, Canberra and Darwin. Available at [online source]: http://www.deh.gov.au/ biodiversity/publications/series/paper3/index.html\#contents

- 1997, 'LI-ANTHAWIRRIYARRA, People of the Sea: Yanyuwa Relations with their Maritime Environment', PhD thesis, Northern Territory University. 
- 2001, 'Landscapes of the Mind, Landscapes of the Spirit: Negotiating a Sentient Landscape', in Working on Country: Indigenous Environmental Management of Australia's Lands and Coastal Regions, R. Baker, J. Davies and E. Young (eds), Oxford University Press, Melbourne: 295-304.

- 2006, 'The Social, Economic and Historical Construction of Cycad Palms among the Yanyuwa', in The Social Archaeology of Indigenous Societies, B. David, B. Barker and I. J. McNiven (eds), Aboriginal Studies Press, Canberra: 161-183.

— with J. Kirton and the Yanyuwa Community. 1992, 'Yanyuwa Wuka: Language from Yanyuwa Country, A Yanyuwa Dictionary and Cultural Resource', unpublished document.

Crossley, N. 1994, The Politics of Subjectivity: Between Foucault and MerleauPonty, Aldershot, Avebury.

Davidson, J. and C. Milligan 2004, 'Embodying Emotion Sensing Space: Introducing Emotional Geographies', editorial, Social and Cultural Geography, vol. 5, no. 4: 523-532.

Hoelscher, S. and D. Alderman 2004, 'Memory and Place: Geographies of a Critical Relationship', Social and Cultural Geography, vol. 5, no. 3: 347-355.

Hooper, P. 1978, 'Cycad Poisoning in Australia: Etiology and Pathology', in Effects of Poisonous Plants on Livestock, R. Keeler, K. van Kampen and L. James (eds), Academic Press, New York: 337-347.

Journey East/Buwarrala Akarriya 1988, Marndaa Productions in association with the Yanyuwa Community, Producer: Debbie Sonnenberg, Script: Jan Wositzky.

Kearney, A. 2005, 'An Ethnoarchaeology of Engagement: Yanyuwa Country and the Lived Cultural Domain', PhD thesis, University of Melbourne.

- 2009. Before the Old People and Still Today: An Ethnoarchaeology of Yanyuwa Places and Narratives of Engagement. Australian Scholarly Publishing, North Melbourne.

- 2008, 'Gender in Landscape archaeology', in World Archaeology Congress, Landscape Archaeology Reader, B. David (ed.), Left Coast Press, Walnut Creek, California: 247-255.

- and J. Bradley 2006, 'Landscapes with Shadows of Once Living People: The Kundawira Challenge', in The Social Archaeology of Indigenous Societies: Essays on Aboriginal History in Honour of Harry Lourandos, B. David, I. J. McNiven and B. Barker (eds), Aboriginal Studies Press, Canberra: 182-203. 
Kearns, R. and L. Berg 2002, 'Proclaiming Place: Towards a Geography of Placename Pronunciation', Social and Cultural Geography, vol. 3, no. 3: 283-302.

Merleau-Ponty, M. 1962, Phenomenology of Perception, translated by C. Smith, Routledge and Kegan Paul, London and New York.

Nora, P. 1989, 'Between Memory and History: Les Lieux de Memoire', Representations 26: 7-25.

Northern Territory Government n.d., Search Certificate: Pastoral Lease 00685 [Manangoora Pastoral Lease], Volume 054 Folio 043, Search date: 5 September 2003.

Rose, D. B. 1996, Nourishing Terrains; Australian Aboriginal Views of Landscape and Wilderness, Australian Heritage Commission, Canberra.

- 2000, Dingo Makes Us Human: Life and Land in an Australian Aboriginal Culture, Cambridge University Press, Cambridge.

- and A. Clarke 1998, Tracking Knowledge: Studies in North Australian Landscapes, NARU, Darwin.

Sharp, N. 2002, Saltwater People: The Waves of Memory, Allen \& Unwin, New South Wales.

Whiting, M. 1963, ‘Toxicity of Cycads', Economic Botany, no. 17: 271-301.

Yanyuwa Families, J. Bradley and N. Cameron 2003, Forget About Flinders: An Indigenous Atlas of the Southwest Gulf of Carpentaria, vol. 1, Australian Institute of Aboriginal Studies, Canberra.

\section{Endnotes}

1. In the Yanyuwa language, wirrimalaru means something of great importance or power. Governments and their various departments are considered to have wirrimalaru; Dreamings and their related ceremonies are also said to have wirrimalaru. The concepts applied by the Yanyuwa to this word cover both the sacred/spiritual and secular nature of their world (Bradley 1988a: 32).

2. Throughout this paper the term 'country' is used. This term is a means of expressing both land and seascapes at once. It is drawn from experience in working with Yanyuwa people and their view that the land and sea are not separate, as Yanyuwa woman Dinah Norman Marrngawi says, "country is all country".

3. The cycad fruit has extremely toxic and carcinogenic qualities (see Whiting 1963; Beaton 1977; Hooper 1978) and meticulous labour-intensive methods are required to prepare it for eating. The songs referred to in this quote relate to the 'power songs' that carry healing capacities for those who may have eaten untreated cycad fruit, or drunk of the water in which still toxic cycad nuts had been soaking (Bradley 2006).

4. Kujika is a song cycle and/or Dreaming path. These song cycles are sung during ceremonial performances. Each semi-moiety has a number of song cycles, all sacred, some secret and sacred. 
They tell of the journeys and actions of the Dreaming ancestors as they crossed the land. There is a sense in which these song cycles are still thought to be resonating through the land as the following statement highlights: "kujika ja-wingkayi ja-wujbanji barra yurrngurmantha ki awarala" - "the song cycles are moving, they are flowing continually within the land" (Bradley et al. 1992: 167). These songs tell the story of the Dreaming as they travelled over the country, everything the Dreaming did is contained in these songs, as one Yanyuwa man said, "they are like maps, they tell us about country, they are maps which we carry in our heads" (Mussolini Harvey 1988 in Bradley 1988a: xi).

5. Nyankarra translates to 'I am being for her that country all the time'.

6. Bush names, referred to as na-wunyingu in Yanyuwa language, are names given to individuals, and are derived from one's father's and father's father's country. These names intimately link a person to a place and are seen as a part of the heritage of any one place. A women whose father's and father's father's country is Manankurra can be given the bush name 'a-Manankurrmara', which translates as 'she who keep the country Manankurra constantly active'. 
Figure 19.1: Map of Kurtjar traditional territory

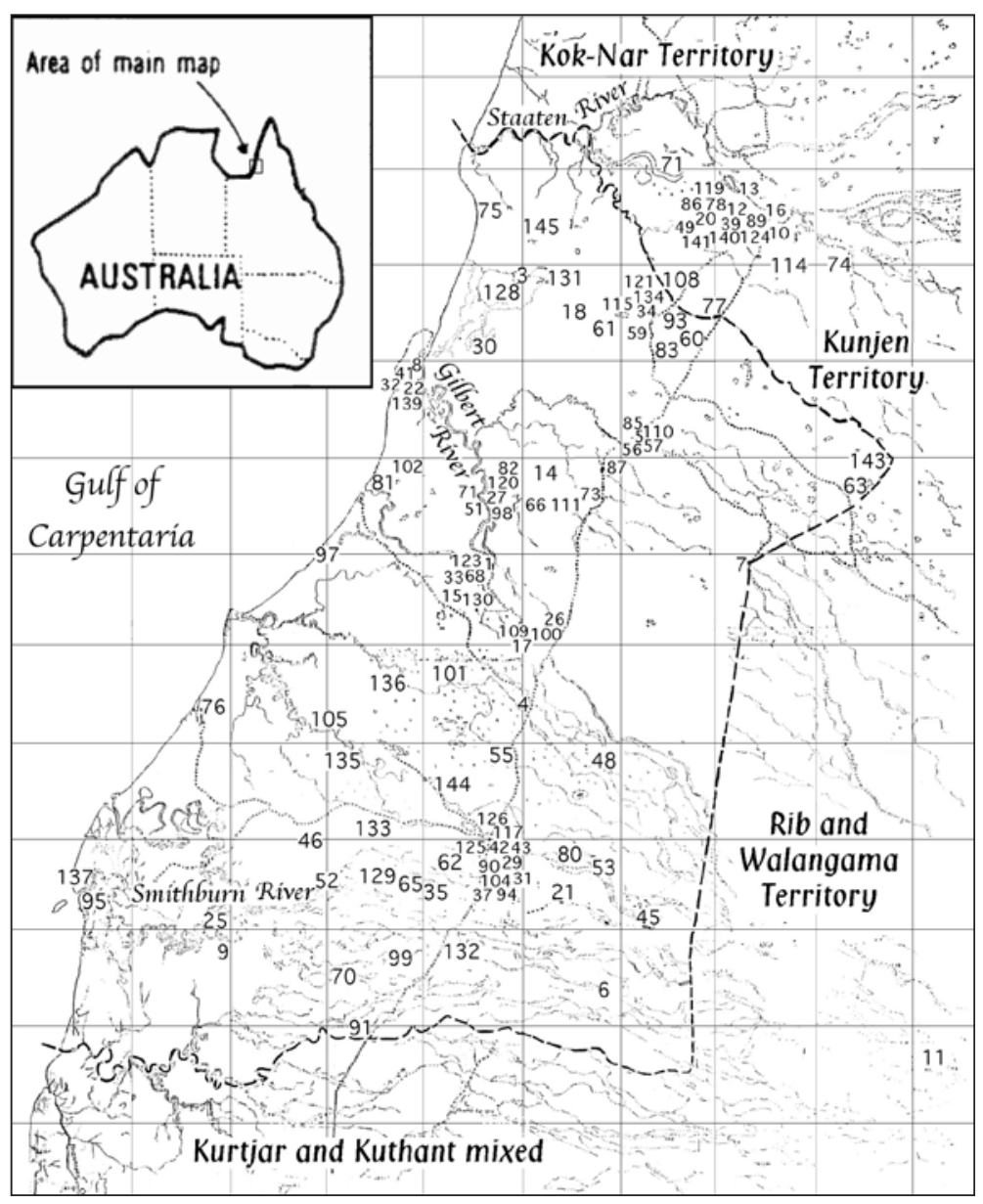

